\title{
Outcomes of Renal Trauma in Indian Urban Tertiary Healthcare Centres: A Multicentre Cohort Study
}

\author{
Bhakti Sarang $^{1,2} \cdot$ Nakul Raykar $^{3,4}$ - Anita Gadgil ${ }^{2,5}$ - Gunjan Mishra ${ }^{6}$ Martin Gerdin Wärnberg ${ }^{7,8}$. \\ Amulya Rattan' $\cdot$ Monty Khajanchi ${ }^{10} \cdot$ Kapil Dev Soni ${ }^{11} \cdot$ Monali Mohan $^{12} \cdot$ Naveen Sharma $^{13}$. $^{2}$ \\ Vineet Kumar $^{14} \cdot$ Deepa KV $^{15} \cdot$ Nobhojit $\operatorname{Roy}^{2,16}$ (D) On behalf of the Towards Improved Trauma Care \\ Outcomes TITCO-India
}

\begin{abstract}
Background Renal trauma is present in $0.5-5 \%$ of patients admitted for trauma. Advancements in radiologic imaging and minimal-invasive techniques have led to decreased need for surgical intervention. We used a large trauma cohort to characterise renal trauma patients, their management and outcomes.

Methods We analysed "Towards Improved Trauma Care Outcomes in India" cohort from four urban tertiary public hospitals in India between 1st September 2013 and 31st December 2015. The data of patients with renal trauma were extracted using International Classification of Diseases 10 codes and analysed for demographic and clinical details. Results A total of 16,047 trauma patients were included in this cohort. Abdominal trauma comprised 1119 (7\%) cases, of which $144(13 \%)$ had renal trauma. Renal trauma was present in $1 \%$ of all the patients admitted for trauma. The mean age was 28 years (SD-14.7). A total of 119 (83\%) patients were male. Majority (93\%) were due to blunt injuries. Road traffic injuries were the most common mechanism (53\%) followed by falls (29\%). Most renal injuries $(89 \%)$ were associated with other organ injuries. Seven of the $144(5 \%)$ patients required nephrectomy. Three patients had grade $\mathrm{V}$ trauma; all underwent nephrectomy. The 30-day in-hospital mortality, in patients with renal trauma, was $17 \%(24 / 144)$.

Conclusion Most renal trauma patients were managed nonoperatively. $89 \%$ of patients with renal trauma had concomitant injuries. The renal trauma profile from this large cohort may be generalisable to urban contexts in India and other low- and middle-income countries.
\end{abstract}

Nobhojit Roy

nobhojit.roy@ki.se

1 Department of Surgery, Terna Medical College and Hospital, New Mumbai, India

2 WHO Collaborating Centre for Research in Surgical Care Delivery in LMIC, Mumbai, India

3 Trauma and Emergency Surgery, Brigham and Women's Hospital, Boston, MA, USA

4 Program in Global Surgery and Social Change, Harvard Medical School, Boston, MA, USA

5 Department of Surgery, Bhabha Atomic Research Centre Hospital, Mumbai, India
6 Department of Surgery, Mahatma Gandhi Mission Medical College and Hospital, New Mumbai, India

7 Department of Global Public Health, Karolinska Institutet, Stockholm, Sweden

8 Function Perioperative Medicine and Intensive Care, Karolinska University Hospital, Solna, Sweden

9 Department of Trauma Surgery and Critical Care, All India Institute of Medical Sciences, Rishikesh, India

10 Department of Surgery, Seth GS Medical College and KEM Hospital, Mumbai, India

11 Critical and Intensive Care, JPN Apex Trauma Hospital, AIIMS, New Delhi, India 


\section{Introduction}

Injuries account for $10 \%$ of global mortality which translates to around 4.5 million annual deaths [1]. It is estimated that more than 1000 non-fatal injuries occur for every injury related death $[2,3]$. Globally, renal trauma is present in approximately $0.5-5 \%$ of patients with traumatic injury and $10-20 \%$ of patients with abdominal trauma [4-6].

The American Association for the Surgery of Trauma (AAST) classifies renal trauma into five grades of increasing severity [7]. Advances in imaging and endovascular techniques in high-income settings (HICs) have resulted in an increase in nonoperative management of renal trauma, including those with high AAST grades (III-V) [8-10]. Nephrectomy in these settings is often reserved for patients with persistent shock or sepsis, or when endovascular techniques or intensive care facilities are limited [10, 11].

Several recent studies from India and other low- and middle-income countries (LMICs) have also described renal trauma management with a nonoperative approach but these are all single centre studies with small sample sizes [12-14]. We used a large trauma cohort encompassing four public urban tertiary healthcare centres in India [15] to characterise patients with renal trauma and observe their management and outcomes.

\section{Methods}

\section{Study design}

We analysed the prospective multicentre cohort "Towards Improved Trauma Care Outcomes (TITCO) in India" [15] cohort from four urban tertiary public hospitals in India between 1st September 2013 and 31st December 2015.

\section{Study setting}

The four hospitals included in the TITCO cohort provide Level 1 trauma services to an urban Indian population.

12 Health Systems Strengthening, Muzaffarpur Field Health Laboratory, CARE-India, Patna, Bihar, India

13 Department of General Surgery, All India Institute of Medical Sciences, Jodhpur, India

14 Department of Surgery, Lokmanya Tilak Municipal Medical College and Hospital, Mumbai, India

15 Department of Surgery, Manipal Hospital, Dwarka, Delhi, India

16 Department of Global Public Health, Karolinska Institutet, 17177 Stockholm, Sweden
Level 1 trauma care facilities in India provide the highest level of definitive and comprehensive coverage of all surgical specialities round the clock [16]. These hospitals in metropolitan cities (Mumbai-2; Delhi-1; Kolkata-1) received direct admissions as well as referrals from other hospitals. The participating hospitals were Jai Prakash Narayan Apex Trauma Centre of All India Institute of Medical Sciences (AIIMS), New Delhi; Lokmanya Tilak Municipal General Hospital (LTMGH) and King Edward Memorial (KEM) Hospital, Mumbai and Seth Sukhlal Karnani Memorial Hospital (SSKM), Kolkata. All sites had expertise and availability for endourology and interventional radiology.

All the study sites had availability of endourology and endovascular modalities like angioembolisation; however, the details of its utility for management of renal trauma have not been mentioned or captured in the data registry. Also, although these modalities were available at these hospitals during the study period, their utility was reserved mainly for elective procedures and not readily available as a part of emergency care of trauma patients.

\section{Eligibility criteria}

The TITCO cohort included all trauma patients who presented to the emergency departments (EDs) of the study hospitals and were admitted for further treatment. Patients who died after arrival but before admission were also included. Patients with isolated limb injury or who were dead on arrival were not included. Patients were followed up for 30 days from the date of admission or until death or discharge from hospital, whichever was longer. The data of patients with renal trauma with or without other organ injuries, from this cohort, were extracted using the International Classification of Diseases 10 codes (ICD-10 Version:2010) [17], ICD code S37.0 specific for renal trauma.

\section{Data collection}

Data were collected prospectively by research officers with a postgraduate degree in health sciences. The research officers received training before the data collection and guidance from the investigators on a weekly basis during the period of data collection. They worked daily through an 8-h shift in rotations with morning, evening and night duties. They used a standardised intake form for data collection and made entries by directly observing the doctors and paramedical staff, engaged in trauma care during their respective duty hours. The data for the patients admitted outside the duty hours were retrieved from patient's medical records the subsequent day. They uploaded the data to a central database weekly and the team of investigators 
from each centre checked the data periodically to ensure quality and consistency of data elements. The Injury Severity Score (ISS) was calculated based on the details of injury, imaging and operative findings by a certified abbreviated injury scale specialist.

\section{Study variables}

We analysed the data of patients with renal trauma for the characteristics including age and gender, mechanism of injury, heart rate (HR) and systolic blood pressure (SBP), Glasgow Coma Score (GCS) and Injury Severity Score (ISS). The data also included information on haemoglobin levels, blood urea nitrogen levels, contrast enhanced computerised tomography (CECT) findings, surgical interventions if any, length of hospital stay and blood transfusion details.

We categorised each renal injury into AAST grades based on the CECT reports and/or operative findings. The renal injuries whose description was not detailed in the CECT reports or operative notes were not assigned any grade and marked as non-gradable (NG).

All the collaborating centres approved the TITCO study in their respective institutional review board, and a waiver of informed consent was granted. This study used anonymised data from the TITCO cohort.

\section{Quantitative variables and statistical methods}

All continuous variables were represented as median and interquartile range and categorical variables as counts and percentages. Age was represented as mean with standard deviation. The data analysis was performed using Microsoft Excel statistical software 2019.

\section{Result}

Over the study period, 16,047 trauma patients were admitted and enrolled in the TITCO cohort. Abdominal trauma comprised $1119(7 \%)$ cases, of which $144(13 \%)$ had renal trauma. Renal trauma was present in $1 \%$ of patients admitted for trauma (Fig. 1).

The demographic and clinical profile of the patients with renal trauma listed is shown in Table 1 . The mean age was 28 years (SD-14.7), age following a unimodal distribution, with young adults (20-40 years), being the most affected (Fig. 2). A total of 119 (83\%) patients were male. Blunt trauma was the predominant mode of injury (93\%). Road traffic injuries (RTIs) were the commonest mechanism $(53 \%)$ followed by falls $(29 \%)$. On sub-categorisation of patients with renal trauma due to RTIs, we observed that pedestrians and motorcyclists constituted around 47\% (36/
76) of patients having renal trauma. Grade $\mathrm{V}$ renal trauma was seen in motorcyclists and drivers. $76 \%$ of patients with renal trauma had no or mild traumatic brain injury (TBI) with GCS $13-15.3 \%$ and $14 \%$ patients had moderate (GCS 9-12) and severe (GCS $\leq 8)$ TBI, respectively. The median ISS was 17 (IQR-9-21). Patients with grade IV and V renal trauma had predominantly severe (16-25) and profound (26-75) ISS. However, the ISS in these patients did not correlate with the need for surgical intervention. A total of $24(17 \%)$ patients with renal trauma were hypotensive $(\mathrm{SBP}<90 \mathrm{~mm} \mathrm{Hg})$ on presentation and $50(35 \%)$ had tachycardia (HR $>100$ beats/minute) (Table 1$)$.

Most patients with renal trauma $(89 \%)$ had other concomitant organ injuries. Only $16(11 \%)$ patients had isolated renal trauma. Splenic (30\%) and liver (27\%) injuries were most associated with renal trauma (Fig. 3).

Operative management $(\mathrm{OM})$ for the kidney was performed in 10 patients. Seven of the $144(5 \%)$ patients had nephrectomy. Of the seven patients who underwent nephrectomy, five were operated within the first $24 \mathrm{~h}$ of admission while the remaining two had delayed nephrectomy (beyond $24 \mathrm{~h}$, exact timing unknown). Three patients underwent primary repair of renal injury (renorrhaphy).

Three patients had grade V trauma; all underwent nephrectomy due to haemodynamic instability. One fourth of patients with grade IV trauma $(n=7)$ underwent OM; 4 patients underwent nephrectomy, none due to haemodynamic instability; 3 had primary repair of the renal injury (Table 2).

The 30-day in-hospital mortality in patients with renal trauma was $17 \%(24 / 144)$. The mortality in patients with renal trauma as per AAST grades is shown in Table 2. However, due to overall small number of patients with renal trauma with very few patients having isolated renal trauma, its contribution to the mortality could not be determined.

\section{Discussion}

We found renal trauma to be present in around $1 \%$ of patients admitted for trauma and $13 \%$ of patients with abdominal trauma in this Indian cohort. This is comparable to global trauma literature with renal trauma present in around $0.5-5 \%$ of patients admitted for trauma and $8-20 \%$ of patients with abdominal trauma $[4,6,7,18]$.

Most patients were managed conservatively (NOM) with only 7 (5\%) undergoing nephrectomy. Nephrectomies were only performed in patients with grade IV \& V renal trauma. Indian centres have previously reported nephrectomy rates of $12-16 \%$, with those in grade $\mathrm{V}$ approaching $90 \%$ [12, 19]. A study from South Africa, a setting similar to the Indian LMIC context, demonstrated high 
Fig. 1 Recruitment algorithm

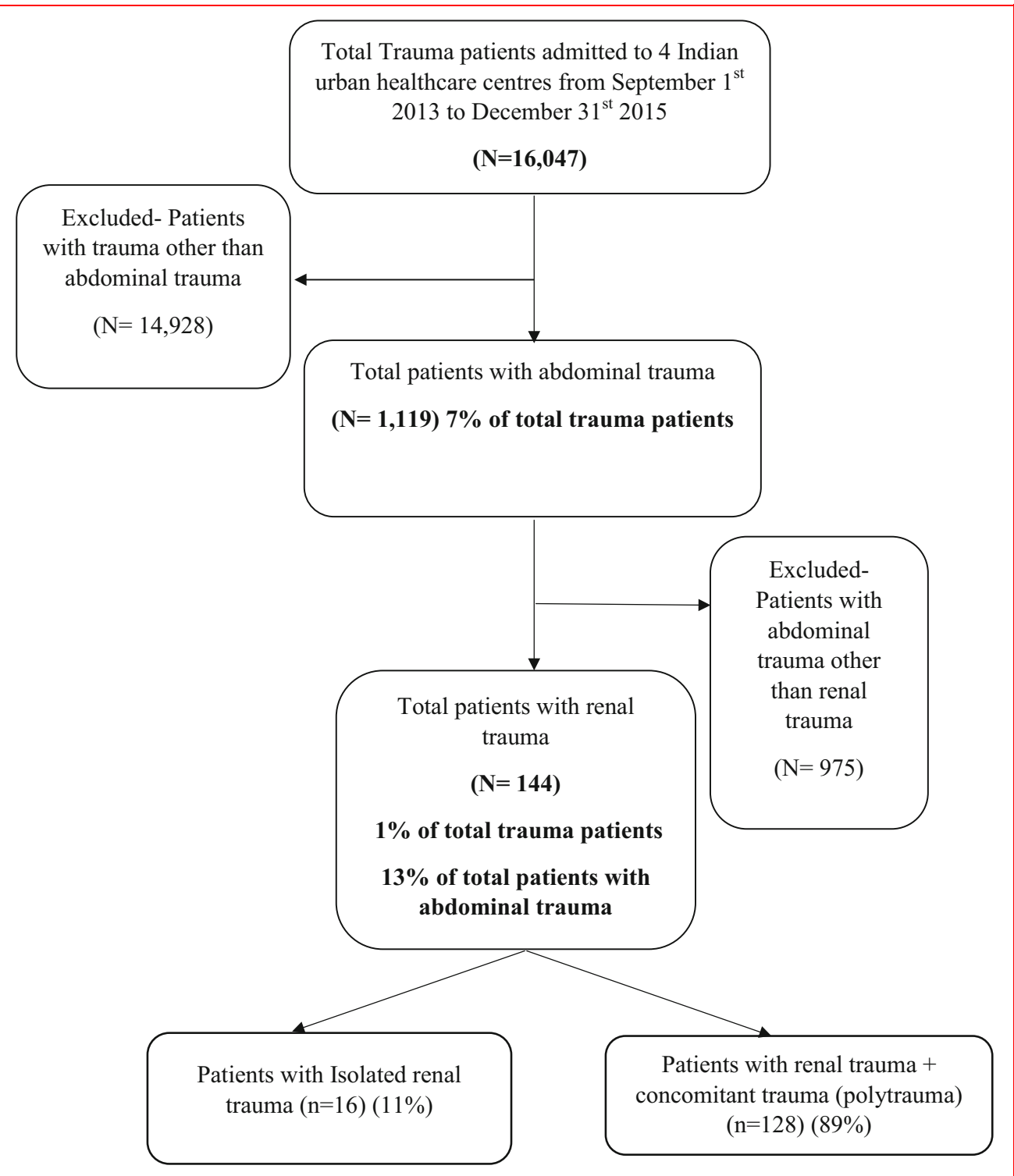

nephrectomy rates of $40 \%$ for grade IV and $89 \%$ for grade $\mathrm{V}$ in predominantly blunt renal trauma [20]. Contrary to this, another South African study from a tertiary level major trauma centre utilising endovascular and endourological interventions for trauma management, demonstrated nephrectomy rates of $10.5 \%$ for grade IV and $25 \%$ for grade $\mathrm{V}$ patients with blunt renal trauma [21]. A genitourinary trauma study by the AAST demonstrated nephrectomy rates of $15 \%$ for grade IV and $62 \%$ for grade V [10], and a Canadian study by Mann et al. demonstrated only a $4 \%$ nephrectomy rate for high-grade renal trauma [22]. As compared to HICs and LMIC setups practicing minimally invasive endovascular and endourological techniques, the nephrectomy rate was higher in our cohort for grade $\mathrm{V}$ renal trauma. However, a true comparison may not be feasible due to the small number of patients with grade $\mathrm{V}$ renal trauma in our cohort and all of these patients being hemodynamically unstable, at least upon arrival. Further, while angioembolisation was available in all the centres included in this study, utilisation of these resources is not recorded in our dataset. Additionally, access to these resources in the emergency trauma setting can be variable based on time of day and existing case volume.

Renal trauma often occurs as a part of polytrauma. $89 \%$ of renal trauma patients in this study had concomitant injuries. The most common organs affected were the spleen and the liver. This is comparable to the literature around the world with $80-95 \%$ patients having associated organ injuries [7, 23, 24]. We observed a relatively high mortality in patients with low-grade renal trauma and other concomitant injuries. This high mortality was likely due to 
Table 1 Demographics and Clinical Profile of Patients with Renal Trauma

\begin{tabular}{|c|c|c|}
\hline Variables & $\begin{array}{l}\text { Value } N=144 \\
N(\%)\end{array}$ & Missing values $(n)$ \\
\hline Age & $28(14.7)$ & 0 \\
\hline Males & $119(83)$ & 0 \\
\hline Adults ( $>18$ years of age) & $115(80)$ & 0 \\
\hline Mechanism of injury (MOI) & $76(53)$ & 0 \\
\hline Road traffic injury & $41(29)$ & \\
\hline Falls & $14(10)$ & \\
\hline Assault & $5(4)$ & \\
\hline Railway injuries & $8(6)$ & \\
\hline \multicolumn{3}{|l|}{ Others } \\
\hline Blunt injury & $134(93)$ & 0 \\
\hline Isolated renal trauma & $16(11)$ & 0 \\
\hline Renal trauma + Concomitant trauma & $128(89)$ & \\
\hline AAST grade & $14(10)$ & \\
\hline I & $45(31)$ & \\
\hline II & $37(26)$ & \\
\hline III & 27 (19) & \\
\hline IV & $3(2)$ & \\
\hline $\mathrm{V}$ & $18(13)$ & \\
\hline \multicolumn{3}{|l|}{ NG } \\
\hline HR & $90(80-109)$ & 2 \\
\hline Tachycardia (HR > 100 bpm) & $50(35)$ & \\
\hline SBP & $115(102-124)$ & 4 \\
\hline Hypotension (SBP < 90 mmHg) & $24(17)$ & \\
\hline GCS & $20(14)$ & 10 \\
\hline Severe TBI $(\leq 8)$ & $5(3)$ & \\
\hline Moderate TBI (9-12) & $109(76)$ & \\
\hline \multicolumn{3}{|l|}{ Mild TBI (13-15) } \\
\hline ISS & $17(9-21)$ & 34 \\
\hline Haemoglobin $(\mathrm{gm} / \mathrm{dl})$ & $11.6(9.6-13.2)$ & 10 \\
\hline Blood transfusion in the first $24 \mathrm{~h}$ & $39(27)$ & \\
\hline Blood urea nitrogen (mg/dl) & $27(20.3-35.5)$ & 11 \\
\hline Length of stay (days) & $6(4-15)$ & 1 \\
\hline
\end{tabular}

Continuous variables are represented by median and interquartile range

Categorical variables are represented as counts and percentages

Age represented as mean and standard deviation, TBI- Traumatic Brain Injury

All percentages rounded up to the closest integer, NG- Non-Gradable based on CECT or operative findings

serious concomitant injuries, as isolated renal trauma in our cohort was rare.

The mean age of patients afflicted with renal trauma in this study was 28 years. Age demonstrated a unimodal distribution with young adults being the most affected. We also observed a male predominance. Blunt injuries, particularly RTIs and falls, were the most common mechanism . This is similar to the global literature, wherein patients afflicted with renal trauma have been predominantly young, with a mean age between 30 and 40; mostly male, reflecting $70-90 \%$ of cases; and due to blunt trauma mechanism, particularly road traffic injury [7, 23, 25]. Renal trauma was observed mainly in pedestrians and motorcyclists among the RTIs. Pedestrians and motorcyclists are vulnerable to renal trauma, and these injuries may be unique to LMIC settings like India [10] and may form basis for future work. 
Fig. 2 Age distribution in patients with renal trauma

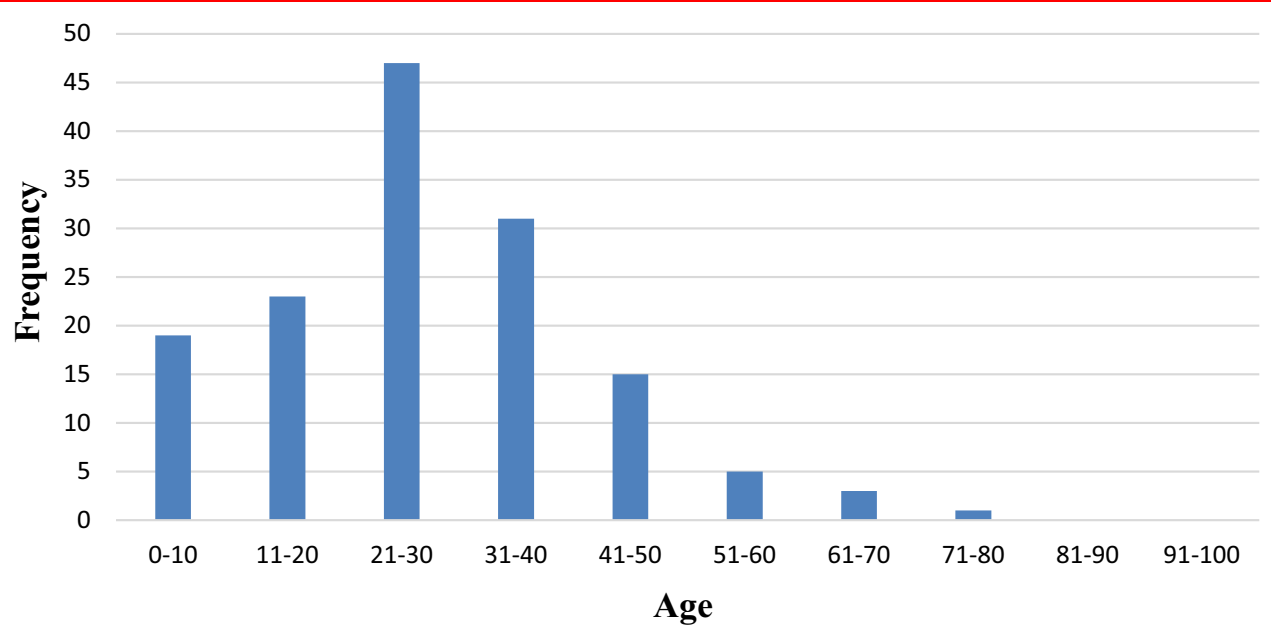

Fig. 3 Organ injuries associated with renal trauma

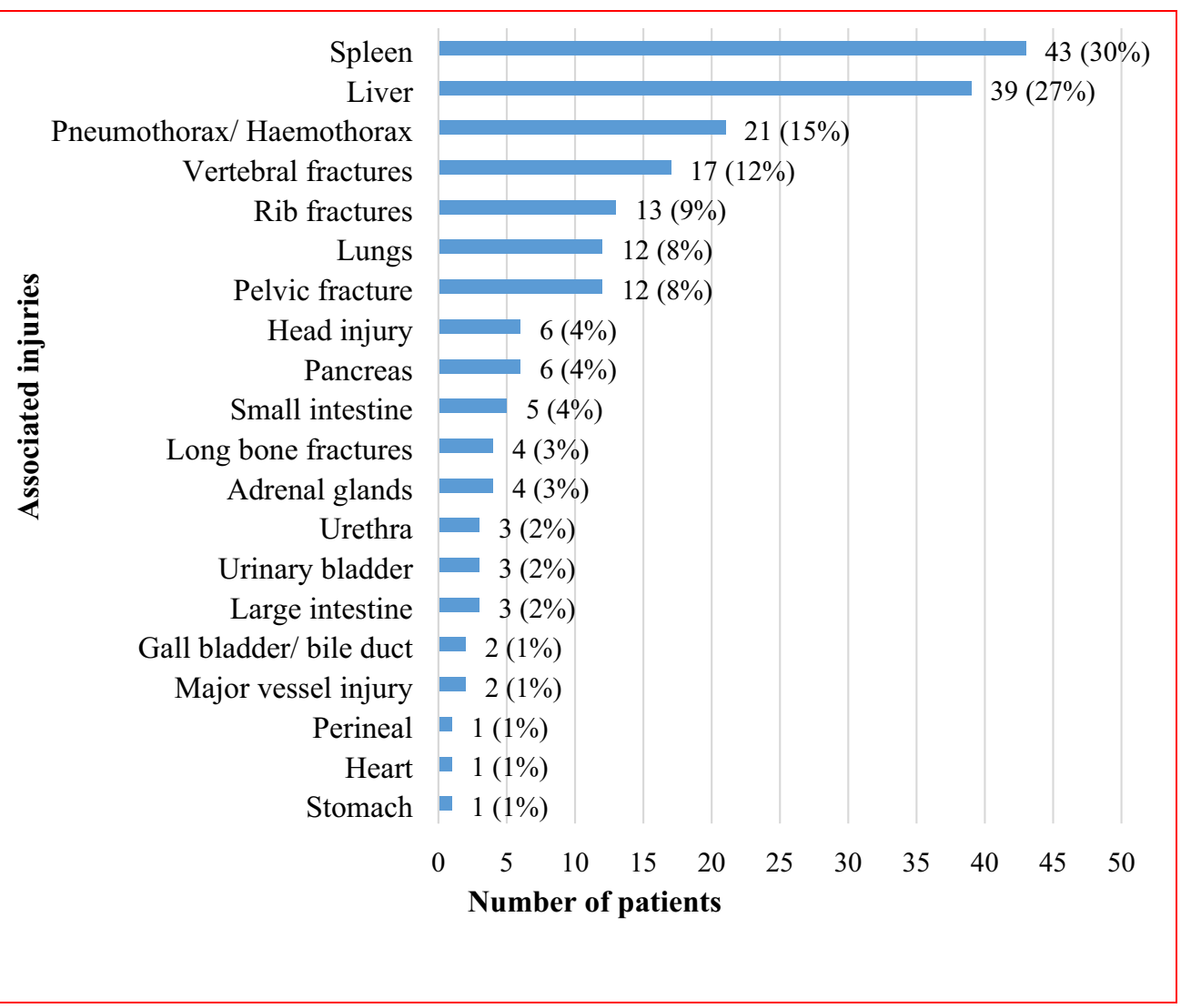

A strength of this analysis is the large dataset, representing multiple level 1 public urban healthcare centres across India, allowing a more complete representation of the renal trauma patient profile, injury grade, and management strategies employed.
A limitation of our analysis is the limited information on the use of endovascular therapies. Additional research is needed to understand the impact of the availability of endovascular therapy, or its absence, on the management of high-grade renal trauma in the Indian context. 
Table 2 Management of renal trauma based on the AAST grades

\begin{tabular}{lllllll}
\hline Grade & NOM & OM (Renal repair/associated injuries) & $\begin{array}{l}\text { OM } \\
\text { Nephrectomy }\end{array}$ & $\begin{array}{l}\text { Nephrectomy } \\
\text { rate }\end{array}$ & $\begin{array}{l}\text { Isolated renal trauma } \\
\text { Mortality }\end{array}$ \\
\hline I $(n=14)$ & 12 & $0 / 2$ & 0 & 0 & 0 & $3(21 \%)$ \\
II $(n(=45)$ & 33 & $0 / 12$ & 0 & 0 & 2 & $9(20 \%)$ \\
III $(n=37)$ & 28 & $0 / 9$ & 0 & 0 & $3(8 \%)$ \\
IV $(n=27)$ & 16 & $3 / 6^{*}$ & 4 & $15 \%$ & 4 & $4(15 \%)$ \\
V $(n=3)$ & 0 & $0 / 0$ & 3 & $100 \%$ & 0 & $1(33 \%)$ \\
NG $(n=18)$ & 13 & $0 / 5$ & 0 & 0 & 1 & $4(22 \%)$ \\
\hline
\end{tabular}

*2 of the 3 patients undergoing OM for renal repair were also operated for concomitant splenectomy. Hence 3/6, wherein 2 patients are common on both sides

OM- Operative Management, NOM- Nonoperative Management, NG- Non-Gradable

\section{Conclusion}

Renal trauma is present in $1 \%$ of patients admitted for trauma and $13 \%$ of patients with abdominal trauma. Most renal trauma patients were managed nonoperatively. Most patients (89\%) with renal trauma had concomitant injuries. The renal trauma profile from this large cohort may be generalisable to other urban healthcare centres in India and urban contexts in other LMICs.

Acknowledgements We thank the Thursday Truth Seekers (TTS) and the Towards Improved Trauma Care Outcomes (TITCO), India, research team for their support.

Funding Open access funding provided by Karolinska Institute. The data collection was funded by the Swedish National Board of Health and Welfare and the Laerdal Foundation. There is no funding to report on this submission.

\section{Declarations}

Conflict of interest There is no conflict of interest to disclose from any of the authors.

Ethics clearances and consent The TITCO project was granted waivers of informed consent from all study centres. The study received approval from the institutional ethics committee of the four centres involved in the study. The ethics approval registration numbers were EC/NP-279/2013 RP-01/2013 from the All India Institute of Medical Sciences Ethics Committee, IEC/11/13 from the Lokmanya Tilak Municipal Medical College and Lokmanya Tilak Municipal General Hospital institutional ethics Committee, IEC/279 from the Institute of Post Graduate Medical Education and Research (IPGME\&R) Research Oversight Committee (Institutional Ethics Committee) and IEC(I)OUT/222/14 from the Seth GS Medical College and King Edward Memorial Hospital Institutional Ethics Committee.

Open Access This article is licensed under a Creative Commons Attribution 4.0 International License, which permits use, sharing, adaptation, distribution and reproduction in any medium or format, as long as you give appropriate credit to the original author(s) and the source, provide a link to the Creative Commons licence, and indicate if changes were made. The images or other third party material in this article are included in the article's Creative Commons licence, unless indicated otherwise in a credit line to the material. If material is not included in the article's Creative Commons licence and your intended use is not permitted by statutory regulation or exceeds the permitted use, you will need to obtain permission directly from the copyright holder. To view a copy of this licence, visit http://creativecommons. org/licenses/by/4.0/.

\section{References}

1. James SL, Castle CD, Dingels ZV et al (2020) Global injury morbidity and mortality from 1990 to 2017: results from Global burden of disease study 2017-2020. Inj Prev 26:i96-i114. https:// doi.org/10.1136/injuryprev-2019-043494

2. World Health Organization. Injuries and violence (2015) Health in 2015: from MDGs to SDGs: pp 171-188. http://www.who.int/ gho/publications/mdgssdgs/en

3. Alonge O, Agrawal P, Talab A et al (2017) Fatal and non-fatal injury outcomes: results from a purposively sampled census of seven rural subdistricts in Bangladesh. Lancet Global Health Bangladesh 5:e818-e827. https://doi.org/10.1016/S2214109X(17)30244-9

4. Khoschnau S, Jabbour G, Al-Hassani A et al (2020) Traumatic kidney injury: an observational descriptive study. Urol Int 104:148-155. https://doi.org/10.1159/000504895

5. Veeratterapillay R, Fugo O, Haslan P et al (2017) Renal Trauma. J Clin Urol 10:379-390. https://doi.org/10.1177/ 2051415817691642

6. Federico C, Ernest M, Yoram K et al (2019) Kidney and Urotrauma: WSES-AAST guidelines. World J Emerg Surg 14:54. https://doi.org/10.1186/s13017-019-0274-x

7. Knipe H, Gaillard F (2018) AAST kidney injury scale. Radiopedia.

8. Chiron P, Hornez E, Durand X et al (2016) Grade IV renal trauma management. A revision of the AAST renal injury grading scale is mandatory. Eur J Trauma Emerg Surg 42:237-241. https://doi. org/10.1007/s00068-015-0537-5

9. Kirkpatrick B, Nima B, Benjamin B et al (2018) Use of angioembolization in urology: a review. Transl Androl Urol 7:535-544

10. Keihani S, Xu Y, Presson AP et al (2018) Contemporary management of high-grade renal trauma: results from the American association for the surgery of trauma genitourinary trauma study. J Trauma Acute Care Surg 84(3):418-425 
11. Tomer E, Noam K (2018) Renal trauma: the current best practice. Ther Adv Urol 10:295-303. https://doi.org/10.1177/ 1756287218785828

12. Prasad NH, Devraj R, Chandriah GR et al (2014) Predictors of nephrectomy in high grade blunt renal trauma patients treated primarily with conservative intent. Indian J Urol 30:158-160

13. Prakash SV, Mohan CG, Reddy VG et al (2015) Salvageability of kidney in Grade IV renal trauma by minimally invasive treatment methods. J Emerg Trauma Shock 8(1):16-20. https://doi.org/10. 4103/0974-2700.145418

14. Syarif PAM, Kholis K et al (2020) Renal trauma: a 5-year retrospective review in single institution. Afr J Urol 26:61

15. Roy N, Gerdin M, Ghosh S et al (2016) 30-day in-hospital trauma mortality in four urban university hospitals using an Indian trauma registry. World J Surg 40:1291299-1307. https://doi.org/ 10.1007/s00268-016-3452-y

16. Capacity Building for developing Trauma Care Facilities in Govt. Hospitals- MoHFW, India 2018

17. ICD-10- International classification of diseases, Tenth RevisionCDC National Center for Health Statistics.

18. Anselmo I, da Costa B, Amend AS et al (2016) Contemporary management of acute kidney trauma. J Acute Dis 5:29-36. https://doi.org/10.1016/j.joad.2015.08.003

19. Rajendra BN, Sharma V, Basavaraj MK et al (2017) Grade V renal injury- short- and long-term outcomes. Open J Trauma 1:020-025
20. Pillay V, Pillay M, Hardcastle T (2019) Renal trauma in a trauma intensive care unit population. S Afr J Surg 57(4):29-32

21. Salem MS, Urry RJ, Kong VY et al (2020) Traumatic renal injury: 5-year experience at a major trauma centre in South Africa. Injury 51(1):39-44. https://doi.org/10.1016/j.injury.2019. 10.034

22. Mann U, Zemp L, Rourke KF (2019) Contemporary management of renal trauma in Canada: a 10-year experience at a level 1 trauma centre. Can Urol Assoc J 13(6):E177-E182. https://doi. org/10.5489/cuaj.5581/

23. Voelzke B, Leddy L (2014) The epidemiology of renal trauma. Transl Androl Urol 3:143-149. https://doi.org/10.3978/j.issn. 2223-4683.2014.04.11

24. Van der Wilden GM, Velmahos GC, Joseph DK et al (2013) Successful non-operative management of the most severe blunt renal injuries: a multicenter study of the research consortium of New England centers for trauma. JAMA Surg 148:924-931. https://doi.org/10.1001/jamasurg.2013.2747

25. McPhee M, Arumainayagam N, Clark M et al (2015) Renal injury management in an urban trauma centre and implications of urological training. Ann R Coll Surg Engl 97(3):194-197. https:// doi.org/10.1308/003588414X14055925061117

Publisher's Note Springer Nature remains neutral with regard to jurisdictional claims in published maps and institutional affiliations. 